
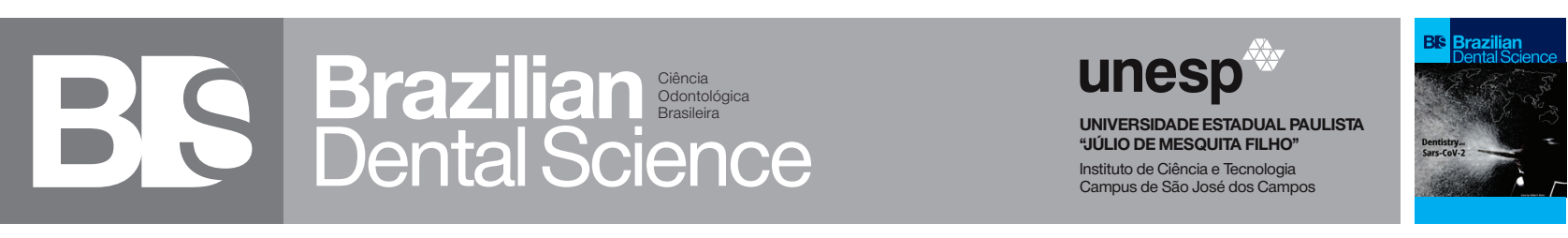

\title{
Temporomandibular disorders: Guidelines and Self-Care for Patients During COVID-19 Pandemic
}

\author{
Desordem Temporomandibular: Orientações e Autocuidados para Pacientes Durante a Pandemia do COVID-19
}

\begin{abstract}
Simone Saldanha Ignacio de OLIVEIRA ${ }^{1}$, Sergio Luiz Melo GONÇALVES ${ }^{2}$, Karin de Mello WEIG ${ }^{1}$, Thales Ribeiro MAGALHÃES FILHO1, Omar Efrain Roque MARTINEZ ${ }^{1}$, Maria Theresa Alves da Cunha KALIL ${ }^{1}$, George Patrick BOGGISS ${ }^{3}$, Denise MANDARINO ${ }^{1}$, João Paulo Colesanti TANGANELI ${ }^{4}$, Thiago Sousa ALMADA ${ }^{1}$, Martha Alayde Alcantara Salim VENANCIO ${ }^{5}$, Roberto PRADO ${ }^{6}$, Renata Matuck Roque RANGEL ${ }^{1}$, Luciana UEMOTO ${ }^{1}$, Rafael BONATO ${ }^{1}$, Fatima Henriques CANTINI ${ }^{1}$, Sunny Yamaguche Nogueira BARRETO ${ }^{1}$, Taísa CHAGAS $^{1}$, Camila Diuana ALMEIDA ${ }^{1}$, Julio Anibal Tablada SANCHEZ ${ }^{1}$, Jennifer Guedes SOBRAL ${ }^{1}$, Fillipi Babiere MATTA ${ }^{1}$, Edilania Andrade FURLEY ${ }^{1}$, Edicleia Neves LIMA ${ }^{1}$, Karoline Ferreira Farias CATARINO ${ }^{1}$, Julia Mattos FEDOZZI ${ }^{1}$, Bianca BRAVIM ${ }^{2}$, Klenise PARANHOS $^{7}$, Adalsa HERNANDEZ-ANDARA ${ }^{8}$

1 - Center of TMD and Orofacial Pain, School of Dentistry of Federal Fluminense University (UFF) - Rio de Janeiro - RJ - Brazil.

2 - Department of General and Specialized Surgery, School of Medicine of Fluminense Federal University (UFF) - Rio de Janeiro - RJ Brazil.

3 - Department of Pain Control and Palliative Care of Oncology, Antonio Pedro Universitary Hospital, School of Medicine of Fluminense Federal University (UFF) - Rio de Janeiro - RJ - Brazil.

4 - Department of Orofacial Pain, Post-Graduation Program, Nove de Julho University (UNINOVE) - Sao Paulo - Brazil.

5 - Department of Oral and Maxillofacial Surgery, School of Dentistry of Federal University of Espírito Santos (UFES) - Espírito Santo - Brazil.

6 - Department of Maxillofacial Traumatology, School of Dentistry of State University of Rio de Janeiro (UERJ) - Rio de Janeiro - Brazil.

7 - Department of Periodontology and Implant Dentistry, NYU College of Dentistry (NYU) - New York - NY - USA.

8 - Coordenator of Oral Radiology and Imaginology, Felix Boada Clinic, Caracas - Venezuela.
\end{abstract}

\section{ABSTRACT}

Background: Temporomandibular disorder (TMD) belongs to a heterogeneous group of musculoskeletal and neuromuscular conditions involving the temporomandibular joint complex, musculature and adjacent components. These conditions can generate signs and symptoms and be influenced by an altered biopsychosocial condition. Objective: This study aims to seek information to assist the patient in the presence of TMD signs and symptoms and Orofacial Pain, associated with the period of social isolation during the COVID-19 pandemic. Material and methods: For the preparation of this manual, a bibliographic search was performed in the databases PubMed, Latin American and Caribbean Health Sciences Literature (LILACS), BBO (BVS), Scopus, Web of Science and The Cochrane Library, using the keywords: orofacial pain, temporomandibular disorders, bruxism, stress, anxiety, biopsychosocial, diagnosis, self-care with important information on how to reduce and control the signs and symptoms of TMD and Orofacial Pain in this

\section{RESUMO}

Introdução: A Desordem Temporomandibular (DTM) pertence a um grupo heterogêneo de condições musculoesqueléticas e neuromusculares envolvendo o complexo articular temporomandibular, a musculatura e os componentes adjacentes. Essas condições podem gerar sinais e sintomas e serem influenciadas por uma condição biopsicossocial alterada. Objetivo: Esse estudo teve como objetivo buscar informações que possam auxiliar ao paciente na presença de sinais e sintomas de DTM e Dor Orofacial associado ao período de isolamento social durante a pandemia do COVID -19. Material e Métodos: Para a elaboração deste manual, foi realizada uma pesquisa bibliográfica nas bases de dados PubMed, Latin American and Caribbean Health Sciences Literature (LILACS), BBO (BVS), Scopus, Web of Science e The Cochrane Library, utilizando as palavras-chaves: dor orofacial, desordem temporomandibular, bruxismo, estresse, ansiedade, biopsicossocial, diagnóstico e autocuidados, com informações importantes sobre como reduzir e controlar os sinais e sintomas de DTM e Dor Orofacial nesse momento de pandemia 
moment of pandemic that we are experiencing a social detachment. Results: The results show that the pandemic of COVID-19 and the need for social isolation, generates psychological impact that raises the pattern of anxiety and can directly affect patients with bruxism and TMD. Conclusion: Psychological factors associated with the pandemic can lead to an increased risk of developing, worsening and perpetuating bruxism, especially waking bruxism and TMD, so dentists should be aware of the occurrence of signs and symptoms to manage the multifactorial aspects of this condition. At that time, individual self-management strategies are advised for the patient, which consist of self-massage techniques, body education, exercise practices, sleep hygiene, meditation also the use of mobile apps and online tools that facilitate this activity.

\section{KEYWORDS}

Orofacial pain; Temporomandibular disorders; Bruxism; Stress; Anxiety; Biopsychosocial; Diagnosis; Self-Care; COVID-19. que estamos vivenciando um distanciamento social. Resultados: Os resultados mostram que a pandemia de COVID-19 e a necessidade de isolamento social, gera impacto psicológico que eleva o padrão de ansiedade e pode afetar diretamente pacientes com bruxismo e DTM. Conclusão: Fatores psicológicos associados à pandemia podem levar a um maior risco de desenvolver, piorar e perpetuar o bruxismo, principalmente bruxismo de vigília e DTM, por isso os cirurgiões-dentistas devem estar atentos a ocorrência de sinais e sintomas para gerenciar os aspectos multifatoriais dessa condição. Aconselha-se, nesse momento, estratégias individualizadas de autogerenciamento para o paciente que consistem em técnicas de automassagem, educação corporal, práticas de exercícios, higiene do sono e meditação. Além do uso de aplicativos digitais e ferramentas online facilitadores dessa atividade.

\section{PALAVRAS-CHAVE}

Dor Orofacial; Desordem Temporomandibular; Bruxismo; Estresse; Ansiedade; Biopsicossocial; Diagnóstico; Autocuidados; COVID-19.

\section{BACKGROUND}

$\mathrm{T}$ he COVID-19 pandemic affected the functioning of routine medical and dental services, restricting it only to emergency care, thereby generating a direct potential impact on the treatment of oral diseases, especially in patients with psychosomatic disorders such as oral mucosa disorders, temporomandibular disorders and bruxism that are directly influenced by the emotional state of these patients [1].

According to the American Academy of Orofacial Pain, Temporomandibular Disorder (TMD) belongs to a heterogeneous group of musculoskeletal and neuromuscular conditions involving the temporomandibular joint complex, musculature and adjacent components [2].

Bruxism, according to the 2018
Consensus, presents itself as waking bruxism, as a behavioral muscle activity of an awake individual that is characterized by being repetitive, with or without dental contact, and jaw movement as a habit may occur. Sleep Bruxism was considered a masticatory muscle activity during sleep characterized as rhythmic (phasic) or non-rhythmic (tonic) however it is not considered as a movement disorder or sleep disorder in healthy individuals. Considered a risk factor for the appearance of TMD signs and symptoms [3].

The dentist must observe the patient fully [4], with a multidisciplinary approach, paying attention to lifestyle and focusing on the prevention of signs and symptoms. In case of persistence or refractory to treatment and guidelines, the patient should be referred to the specialist for TMD and Orofacial Pain [5].

The specialty of TMD and Orofacial Pain, 
recognized in Brazil in 2003 and in the USA in 2020, was defined as a specialty in Dentistry, which includes assessment, diagnosis and treatment of patients with orofacial pain disorders and temporomandibular disorders [5].

This study aims to seek information to assist the patient in the presence of TMD signs and symptoms and Orofacial Pain, associated with the period of social isolation during the COVID-19 pandemic.

\section{MATERIAL AND METHODS}

For the elaboration of these guidelines, a bibliographic search was performed in the databases PubMed, Latin American and Caribbean Health Sciences Literature (LILACS), BBO (BVS), Scopus, Web of Science and The Cochrane Library, using the keywords: orofacial pain, temporomandibular disorders, bruxism, stress, anxiety, biopsychosocial, diagnosis, self-care, COVID-19. Articles from randomized controlled trials (RCT's), casecontrol studies, cohort studies, cross-sectional studies, prospective and retrospective studies, series and case reports, and review articles related to the topic could be used, as well as updated books with important information on how to reduce and control the signs and symptoms of TMD and Orofacial Pain in this moment of pandemic that we are experiencing a social detachment.

\section{RESULTS}

In the outbreak of COVID-19 there was a prevalence of signs and symptoms of TMD and orofacial pain that has been increasing during the pandemic period, in relation to the increase in chronic pain, dry mouth, burning mouth syndrome, bruxism, periodontal diseases and stress-related illnesses [1].

Temporomandibular disorders and orofacial pain can develop due to different conditions and present different diagnoses due to their multifactorial etiology. The most common pictures of muscle pain are local myalgia, myofascial pain due to spreading and referred pain [2].

Joint pain can be caused by incoordination of the condyle-disc complex, which causes mandibular dislocations and locks, inflammatory and degenerative disorders [2].

The most common signs and symptoms in TMDs are myalgia and arthralgia, crackling and crackling, jaw deviations, asymmetries, difficulties in biting and chewing food, tiredness in speech, muscle fatigue, limited mouth opening, pain when performing functional movements, difficulty in closing the mouth, sudden malocclusion resulting from a mandibular dislocation, mandibular locking, headache and pain in the auriculotemporal region, tinnitus, among other otological signs $[2,6,7,8]$.

Among TMD comorbidities and Orofacial Pain, such as headache associated with TMD, primary headache, migraine, tensiontype headache, fibromyalgia, rheumatoid arthritis, neck pain, low back pain, and stressrelated pathologies, such as irritable bowel syndrome, professional burnout syndrome or due to autoimmune diseases, where psychosocial issues, psychological and somatic complaints are often related to psychological distress, requiring a careful assessment of biopsychosocial factors $[9,10,11,12,13]$.

Wake-up bruxism is associated with psychosocial factors such as anxiety, stress and somatic causes, and patients with high levels of stress are up to 6 times more likely to develop this condition [14].

The anxiety-related processes occur in the CNS and involve interactions between the prefrontal cortex, limbic, paralymbic structures and motor regions of the brain stem that lead to motor and physiological responses [15].

Therefore, muscle contraction in waking bruxism may be part of the body's defense behavior associated with anxiety and stress, 
increasing significantly in this period of the pandemic [15].

The presence of bruxism can have harmful implications for oral health [16]. For patients with awake bruxism and sleep bruxism, it is recommended to acquire the habit of keeping the teeth unattached, with the lips sealed in the resting position. Besides the use of an occlusal splint to improve painful symptoms, protect teeth from dental wear and fractures [17].

The investigation of sleep quality is also another very important factor in the evaluation of patients with bruxism. Sleep is a physiological need for nutrition and maintenance of metabolism. According to the Brazilian Association of Sleep Medicine, the most common sleep disorders are insomnia and obstructive sleep apnea. Insomnia is characterized by the difficulty of initiating sleep, maintaining it continuously during the night and waking up early. [18,19]

Obstructive sleep apnea is defined by the obstruction of the upper airways during sleep, leading to rapid respiratory arrest. In this case, for patients who require the use of CPAP therapies, the use of oral devices because they do not generate aerosols and because they are easily disinfected were considered to be the first line of therapy at this time of the COVID-19 pandemic [20,21].

Patients need to avoid eating heavy food and consuming alcoholic beverages or those with caffeine close to bedtime, as well as maintaining a regular sleep routine. In addition, intense physical exercise should not be done close to bedtime and the room should be kept dark and quiet. Finally, one should avoid using electronic equipment with high screen brightness and avoid watching TV in bed. Another important point is to avoid postural sleeping positions that generate overload in the articulation and muscles of the face region $[18,19]$.

In children with bruxism, some routine changes may be suggested, such as practicing regular physical activities, avoiding video games or electronic games before going to sleep, maintaining constant sleeping and waking times; taking care of the sleep environment, attenuating light and external noises [16].

In social isolation, greater attention to body posture is recommended during any activity, in order to reduce muscle and joint tension, mainly due to the increased use of cell phones and computers in a sitting position for a long period $[22,23]$.

Oral behavioral habits such as biting objects, lips and tongue, biting nails, supporting your hand on your face, clenching your teeth and grinding them, chewing food unilaterally repeatedly, among others, can lead to pain or even make your own maintenance [24]. One form of prevention for these triggers is to pay more attention to the habit of keeping teeth unattached during the waking period $[17,24]$.

The situation of isolation and social distance that we are experiencing can trigger or increase stress, anxiety and depression and the use of relaxation techniques provides the reestablishment of a positive connection with reality in relation to the regulation of emotions, improvement of anguish and disabilities, decreased fear, improved acceptance and perception of pain, reduced catastrophizing psychology, increased concentration and improved quality of life $[25,26]$.

It is worth mentioning the importance of treatments that aim to help control these symptoms, such as psychotherapy, meditation, as well as improving sleep quality $[25,26]$.

Meditation and mindfulness practices can help the mental health of patients and the general population during this global pandemic that we are experiencing due to covid-19 [27]. The use of meditation practice as a way of accepting the present moment and self-control of the situation generated for this pandemic. Learning to be aware and mindful of breathing, promotes physical and mental relaxation, useful for managing chronic pain 
and improving physical functioning [25,26, 27].

Among various therapeutic resources, clinical self-care protocols are used as an adjunct to clinical and physical therapy treatment in patients who are elective to conservative, non-invasive treatment; it has low cost and provides the patient with an active participation in its rehabilitation and pain management process [28].

The self-care techniques consist of selfmassage maneuvers of tense and painful areas of the masticatory muscles (the Temporal and Masseter muscles are more accessible), mandibular relaxation and coordination exercises, stretching and thermotherapy exercises associated with individualized assessment, guidance and treatment awareness $[28,29,30]$.

In case of acute or chronic pain present in Temporomandibular Disorders, treatment can be drug-based, however Temporomandibular Pain needs to be evaluated by a specialist in TMD and Orofacial Pain, as it can present different types of typology among the most varied patients. Drug indications should be individualized by type of patient, alerting to the fact of avoiding medication abuse and self-medication [31,32].

Acute pain presents itself as a condition mainly associated with trauma [32] or in cases of maintaining the patient in a certain position (for example, joint pain after a dental procedure that has lasted a long period); in these cases, therapy will be based on a concept that pain is basically somatic, hardly neuropathic or mixed. Therefore, treatment will be based on some main analgesia fronts, preferably performed with an oral, non-opioid analgesic, such as Dipyrone or Paracetamol, with weak opioids, such as Codeine and Tramadol used only in refractory cases [32]; anti-inflammatory drugs, the preference in these cases is that the medication be used for the shortest possible time, thus avoiding the main side effects, especially those related to the gastrointestinal tract and renal function, the main trend being the use of Ibuprofen or Naproxen [33]. The use of hormonal antiinflammatory drugs (corticosteroids), at first, are not indicated in these cases at first, being reserved for prolonged and refractory cases $[32,33]$; muscle relaxants and the action of muscle relaxation will have an important adjuvant effect on analgesia, the most used of which are Cyclobenzaprine, Carisoprodol and Baclofen [32].

For chronic pain that is usually associated with postural errors [30], chronic inflammatory or rheumatologic diseases (for example, rheumatoid arthritis) [31, 32]. In such cases, therapy will be based on the concept that pain is generally mixed (somatic and neuropathic), although in most cases the somatic component is the most evident. Nevertheless, following mainly the concept of Total Pain (in which pain is not only a physical experience, but involves a psychic, emotional / affective and spiritual component) $[31,32,33]$, in which the treatment must contemplate the maximum of possible components, and be personalized for each individual: analgesia: as in acute pain, it should be performed with an oral analgesic, non-opioid, such as paracetamol or dipyrone, with weak opioids, such as codeine and tramadol [33], used more often in their failure, but with results often frustrating [31, 32]. It is worth remembering that analgesia, in most of these cases, is adjuvant to other treatments; anti-inflammatory drugs: whenever possible, the use of this type of medication is avoided, with some exceptions, such as periods of exacerbation with worsening of pain, when used for short periods) or when they are part of the treatment of associated diseases [32]; tricyclic antidepressants: option in cases with a very evident neuropathic component, used at night due to possible drowsiness, the most used being Amitriptyline [31, 32, 33]; anticonvulsants: main medication used in cases of chronic pain, either as main medication or as adjuvant medication, acting both on somatic and neuropathic pain mechanisms. 
Gabapentin and Pregabalin are the drugs of choice, as they have few drug interactions and are highly effective in cases of neuropathic pain. They may need adjustments for patients' age and / or renal function [31, 32, 33].

The use of Selective Serotonin and Noradrenaline Reuptake Inhibitors (SSRE) for orofacial pain has few studies, being used in resistant cases or as adjuvants in mixed pain, mainly fluoxetine, venlaflaxine, duloflaxine and sertraline. Recent studies have shown that these drugs can have adverse effects such as bruxism, stimulate movement disorder, as a side effect, identifying in these cases that these drugs should be discontinued or replaced with other drugs [31], and also alerting the patient to seek a Specialist in TMD and Orofacial Pain or talk to your doctor for a new therapeutic approach.

Regarding drug treatment in the case of bruxism, it is more like an adjuvant treatment, acting on some causes that may be main or secondary to the disease, such as stress and anxiety [31,32]. In the same way, medications that assist in the treatment of pain caused by bruxism can and should be used, in case it will bother the patient a lot [32]. The use of patches with patches with cannabidiol has also been studied, however these studies are still in the early stages and their use is not yet recommended [33].

In cases of treatment for anxiety and / or stress, use anxiolytics such as Alprazolan or Clonazepan in low doses and for short periods; in cases of analgesia: Dipyrone or Paracetamol, if necessary; in cases of use of muscle relaxants, the options of choice are Cyclobenzaprine or Baclofen, for short periods of time, as an adjunct to treatment [32].

Studies show that the virus can lead beyond cough, fever, pneumonia, involvement of the central and peripheral nervous system such as impaired taste and smell and neuralgia [32].

Among the most common pictures related to the central nervous system, there is Trigeminal Neuralgia which can present itself as a "shocking" pain, of intense intensity, which lasts a few seconds, and can occur several times a day; it can also affect only one or more branches of the trigeminal nerve, unilaterally; and be associated with autonomic phenomena, in addition to pain (watery eyes, runny nose or congestion, eyelid edema, restlessness and conjunctival hyperemia). The treatment of choice will be medication with the use of anticonvulsants such as Carbamazepine, preferably [32].

In the case of Post-Herpetic Neuralgia, which is usually preceded by skin changes in the region of the face, like vesicles [31,32]; the following characteristics are identified: it occurs due to a reactivation of infection by the varicella-zoster virus; the pain may present soon after the event or up to 6 months afterwards, generally presenting as "burning" or "needles" of strong intensity; when it affects the ophthalmic branch of the trigeminal, eye protection is extremely necessary ; treatment: medicated with several drugs (antidepressants, anticonvulsants, central muscle relaxants); invasive treatment in certain cases may be indicated, but this is rarely indicated (radiofrequency, botulinum toxin, balloon decompression); may show only partial response to treatment [32].

When diagnosed with Atypical Neuralgia of the Face, Pain presents itself as a "shock", of intense intensity, which lasts a few seconds, and can occur several times a day, being extremely rare non-unilateral cases; it is often similar to trigeminal neuralgia, but it has variable duration, as well as it can present with other descriptions, such as "burning", "needles" ; often associated with autonomic phenomena in addition to pain; treatment: medication (usually with anticonvulsants and analgesics), invasive procedures (radiofrequency, balloon compression guided by radioscopy), and its treatment is often difficult or only partial [32]; it may be associated with trigeminal neuralgia corresponding to treatments, trauma and surgical procedures on the skull or face $[31,32]$. 


\section{CONCLUSIONS}

The COVID-19 pandemic and the need for social isolation, generates psychological impact that raises the standard of anxiety and can directly affect patients with bruxism and TMD. Psychological factors associated with the pandemic can lead to an increased risk of developing, worsening and perpetuating bruxism, especially waking bruxism and TMD. Thus, dental surgeons specialized in TMD and orofacial pain must be aware of the occurrence of signs and symptoms to manage the multifactorial aspects that present themselves. Individualized self-management and relaxation strategies are advised; selfmassage techniques and body education; home care that includes routine, food, exercise practices, sleep hygiene, meditation, as well as providing guidance on the use of a range of online tools and devices useful during this period (teledentistry).

\section{REFERENCES}

1. Qu X, Zhou X. Psychological intervention for patients with oral disease during the pandemic period of COVID-19. Zhonghua Kou Qiang Yi Xue Za Zhi. 2020;55(4):235-40. doi:10.3760/cma.j.cn112144-20200213-00053

2. SchiffmanE, Ohrbach R, Truelove E, Look J, Anderson G, Goulet JP, et al. Diagnostic criteria for temporomandibular disorders (DC/TMD) for clinical and research applications: recommendations of the international RDC/TMD Consortium Network* and orofacial pain special interest groupt. J Oral Facial Pain Headache. 2014;28(1):6-27. doi:10.11607/jop.1151

3. De la Torre Canales G, Bonjardim LR, Poluha RL, Soares FFC, Guarda-Nardini $\mathrm{L}$, ContiPR, et al. Correlation between physical and psychosocial findings in a population of temporomandibular disorder patients. Int J Prosthodont. 2020;33(2):155-9. doi:10.11607/ijp.5847

4. Sarycheval, Yanushevich 0, Minakov D. Diagnostics of non-carious lesions of dental hard tissues with the methods of optical spectroscopy and radiography. Braz Dent Sci 2020 Apr / Jun;23(2):1-8. doi: https://doi.org/1014295/bds.2020. V23i2.1866

5. Fricton J, Crandall JA. Orofacial pain as a new dental specialty. Cranio. 2020;38(2):69-72. doi:10.1080/08869634.2020.1716140

6. Sassi FC, Silva AP,Santos RKS, Andrade CRF.Oral motor rehabilitation for temporomandibular joint disorders: a systematic review. AudiolCommun Res. 2018;23:1-13. doi:http://dx.doi.org/101590/2317-6431-2017-1871

7. Bianchini EM, Paiva G, de Andrade CR. Movimentos mandibulares na fala: interferência das disfunccõos temporomandibulares segundo indices de dor [Mandibular movements in speech: interference of temporomandibular disfunction according to pain indexes]. Pro Fono. 2007:19(1):7-18. doi:101590/ s0104-56872007000100002

8. Felicio CM, Faria TG, Silva MAMR, Aquino AMC, Junqueira, P. Temporomandibular disorder: relationships between otological and orofacial symptoms. Rev.Bras. Otorhinolaryngol. 2004 Nov-Dec; 76(6): 786-93.
9. Liu YZ, Wang YX, Jiang CL. Inflammation: the common pathway of stressrelated diseases. Front Hum Neurosci. 2017;11:316. Published 2017 Jun20. doi:10.3389/fnhum.2017.00316

10. Gudsnuk K, Champagne FA. Epigenetic influence of stress and the socia environment. ILAR J. 2012;53(3-4):279-88. doi:10.1093/ilar.53.3-4.279

11. Park C, Rosenblat JD, Brietzke E, Pan Z, Lee Y, Cao B, et al. Stress, epigenetics and depression: a systematic review. Neurosci Biobehav Rev. 2019;102:139-52 doi:10.1016/j.neubiorev.2019.04.010

12. Koutsimani P,Montgomery A, Georganta K. The relationship between burnout, depression, and anxiety: a systematic review and meta-analysis. FrontPsychol. 2019;10:284. Published 2019 Mar 13. doi:10.3389/fpsyg.2019.00284

13. ReicheEM, Nunes SO, Morimoto HK. Stress, depression, the immune system, and cancer. Lancet Oncol. 2004;5(10):617-25. doi:10.1016/S14702045(04)01597-9

14. SmardzJ, Martynowicz H, Wojakowska A, Michalek-Zrabkowska M, Mazur G Wieckiewicz M. Correlation between sleep bruxism, stress, and depression-a polysomnographic Study. J Clin Med. 2019;8(9):1344. Published 2019 Aug 29. doi:10.3390/jcm8091344

15. World Health Organization - WHO. WHO announces COVID-19 outbreak a pandemic [internet]. Copenhagen:WH0;2020 [cited 2020 Apr [19]. Available from:http://www.euro.who.int/en/health-topics/health-emergencies/ coronavirus-covid-19/news/news/2020/3/who- announces-covid-19outbreak-a-pandemic)

16. Firmani M, Reyes M,Becerra N,Flores G, Weitzman M, Espinosa P.Bruxismo de sueño en niños y adolescentes [Sleep bruxism in children and adolescents]. Rev Chil Pediatr.2015;86(5):373-9. doi:10.1016/j.rchipe.2015.05.001

17. Oliveira SS, Pannuti CM, Paranhos KS, Tanganeli.JPC, LaganáDC, Sesma N, et al. Effect of occlusal splint and therapeutic exercises on postural balance of patients with signs and symptoms of temporomandibular disorder. Clin Exp DentRes. 2019;5(2):109-15. Published 2019 Feb 12. doi:10.1002/cre2.136

18. Ohayon M, Wickwire EM, Hirshkowitz M, Albert SM, Avidan A, Daly FJ, et al. National sleep foundation's sleep quality recommendations: first report. Sleep Health. 2017;3(1):6-19. doi:10.1016/j.sleh.2016.11.006

19. Brazilian Sleep Medicine Association [Internet]. [cited 2020 May 10]. Rochester: Brazilian Sleep Medicine Association. Available from: https //abmsono.org/ artigos.html

20. SchwartzD, Addy N, Levine M, Smith H. Oral appliance therapy should be prescribed as a first-line therapy for OSA during the COViD-19 Pandemic. JDent Sleep Med.2020;7(3). doi:https://www.aadsm.org/docs/COVID Position Statement.pdf

21. Masse JF The Role of DMS during the COVID 19 disease crisis: management with CPAP and oral appliances. J Dent Sleep Med. 2020;7(2). doi:http://dx.doi. org/10.15331/jdsm.7116

22. Lee S, Kang H, Shin G. Head flexion angle while using a smartphone. Ergonomics. 2015;58(2):220-6. doi:10.1080/00140139.2014.967311

23. YuZ, James C, Edwards S, Snodgrass SJ. Differences in posture kinematics between using a tablet, a laptop, and a desktop computer in sitting and in standing. Work. 2018;61(2):257-66. doi:10.3233/WOR-182796

24. Ferreira CL, Silva MA, Felício CM. Signs and symptoms of temporomandibular disorders in women and men. Codas. 2016;28(1):17-21. doi:101590/23171782/20162014218

25. Crowley C, Kapitula LR, Munk D. Mindfulness, happiness, and anxiety in a sample of college students before and after taking a meditation course [published online ahead of print, 2020 May 5]. J Am Coll Health. 2020;1-8. doi:10. 1080/07448481.2020.1754839

26. Gu Q, Hou JC, Fang XM. Mindfulness meditation for primary headache pain: a meta-analysis. Chin Med J (Engl). 2018;131(7):829-38. doi:10.4103/03666999.228242 
27. Behan C. The benefits of Meditation and Mindfulness practices during times of crisis such as Covid-19 [published online ahead of print, 2020 May 14]. Ir J Psychol Med. 2020;1-8. doi:10.1017/ipm.2020.38

28. Tenreiro M. ATM Healthy Manual. Rio de Janeiro: Editora Theano;2019.

29. Cassar PM. Manual of therapeutic massage. Sãp Paulo: Manole; 2001.

30. Dutton M. Physioterapia ortopédica. São Paulo: ArtMed;2006.
31. Harper DE Schrepf A ClauwDJ.Pain mechanisms and centralized pain in temporomandibular disorders. JDent Res. 2016;95(10):110208. doi:10.1177/0022034516657070

32. Teixeira MJ.Pain: manual for the clinician. São Paulo: Atheneu; २०06.

33. LobbezooF, Ahlberg J, Raphael KG, Wetselaar P, Glaros AG, Kato T, et al. International consensus on the assessment of bruxism: report of a work in progress. J Oral Rehabil. 2018;45(11):837-44. doi:10.1111/joor.12663

\section{Dra. Simone Saldanha Ignacio de Oliveira}

\section{(Corresponding address)}

Profa. S. S. I. Oliveira; Division of Prosthodontics, Center of DTM and Orofacial

Pain, School of Dentistry, Federal Fluminense University, Niterói, Brazil;

Address: Rua São Paulo 28, Campus do Valonguinho, Centro, Niterói, Rio de Janeiro, Brazil. Zip Code: 24020-150.

E-mail: simone_s_oliveira@hotmail.com

Date submitted: 2020 Jun 01

Accept submission: 2020 Jun 04 